\title{
On plummeting manuscript acceptance rates by the main ecological journals and the progress of ecology
}

\author{
David A. Wardle \\ David A. Wardle (david.wardle@slu.se), Department of Forest Ecology and Management, Swedish University of \\ Agricultural Sciences, SE901-83, Umeå, Sweden
}

Over recent years, there has been a precipitous decline in the acceptance rates for most of the major ecological journals; several journals that accepted 35-40\% of submissions fifteen years ago now have acceptance rates of $15 \%$ or less. In a recent Editorial in this journal, Aarssen (2012) makes the case that these increasingly draconian standards are "a product of gate-keeping elitism, motivated by self-serving goals of journal publishers and editors to elevate impact factors as a symbol of status, and to compete with other journals for that status." As such, the leading ecological journals often actively advertise their impact factor, and highlight that their selectivity means that they publish only the very best of the work that is submitted to them. As Aarssen (2012) notes, to maintain these low acceptance rates and "addiction to impact factor elitism....many editors routinely justify rejection of even high quality papers on the absurd claim of limited space....for printed pages within the journal, despite knowing that paper issues are now redundant." This rationale for journal editors allowing their rejection rates to increase is based on the assumption that by selecting a lower proportion of submissions, the average quality of the papers that they do publish will be higher and thus attract more citations, causing the journal's impact factor to increase. Here I provide a simple analysis which shows that this assumption cannot be supported.

In this analysis, I considered ecological research papers published in each of 7 journals, i.e., PLOS ONE (an open access journal with a $69 \%$ manuscript acceptance rate), Ecology, Oikos, Functional Ecology and Ecology Letters (four mainstream ecological journals that have seen a sharp recent decline in acceptance rates, currently in the order of 10-20\%) and Nature and Science (high profile multidisciplinary journals with acceptance rates of 7-8\%). For each of PLOS ONE and the 4 ecological journals, I selected 30 ecological papers published in 2009 that each reported original research (and avoided reviews or meta-analyses) so that similar sorts of papers could be compared among journals. These 30 papers were selected in a stratified manner so that they were evenly spread across 2009 (as a paper published in January has had more time to accrue citations than one published in December). For Nature and Science, I selected all papers published in 2009 reporting original research on topics that would be appropriate for a general ecological journal; this yielded 26 and 28 papers in Nature and Science, respectively. For each paper selected from each journal, I determined how many times it had been cited by using the Web of Science database in May 2012. The acceptance rate for all but one of the journals was obtained from the journal's web page, recent editorials in the journal, or their Instructions to Authors. For the remaining journal (Ecology Letters) this was obtained by dividing the total number of papers published in 2010 by the total number of papers submitted in 2010 (stated in a recent editorial as 'over 1300').

The results of the analysis are presented in Table 1 . They show that ecological papers published in PLoS $O N E$, which accepts $69 \%$ of submissions, publishes work that on average has a greater impact than papers published in Oikos which accepts $15 \%$ of submissions, and has a comparable impact to those in Ecology and Functional Ecology which respectively accept $20 \%$ and $15 \%$ of submissions. Ecological papers published in $P L O S O N E$ are on average cited less than those in Ecology Letters (with an $11 \%$ acceptance rate) but even here there is considerable overlap; $20 \%$ and $23 \%$ respectively of ecological papers published in $P L O S$ 
Table 1. Journal information, including acceptance rate, Impact Factor (2010 data) and mean and median numbers of citations in May 2012 for ecological research papers published throughout 2009 ( $N=30$ except for Nature $(N=$ $26)$ and Science $(N=28)$ ) according to the Web of Science database.

\begin{tabular}{lcccc}
\hline Journal & $\begin{array}{c}\text { Manuscript } \\
\text { acceptance rate }(\%)\end{array}$ & $\begin{array}{c}\text { Impact factor } \\
\text { (Web of Science) }\end{array}$ & \multicolumn{2}{c}{$\begin{array}{c}\text { Number of citations for ecological } \\
\text { research papers }\end{array}$} \\
\cline { 4 - 5 } & & & Mean & Median \\
\hline PLoS ONE & 69 & 4.4 & 11.6 & 8.0 \\
Ecology & 20 & 5.1 & 11.3 & 9.0 \\
Oikos & 15 & 3.4 & 7.8 & 6.5 \\
Functional Ecology & 15 & 4.6 & 10.7 & 9.0 \\
Ecology Letters & $<11$ & 15.2 & 20.9 & 16.0 \\
Science & $<7$ & 31.3 & 66.9 & 44.0 \\
Nature & 8 & 36.1 & 64.7 & 58.5 \\
\hline
\end{tabular}

$O N E$ have been cited more often than the mean and median research paper published in Ecology Letters, and $27 \%$ and $17 \%$ respectively of research papers published in Ecology Letters have been cited less often than the mean and median ecological research paper published in $P L O S O N E$. In contrast, all ecological papers published in Science and Nature were cited more often than both the median and mean for PLoS ONE (and for Oikos, Functional Ecology and Ecology).

The result that stands out is that ecological papers published in PLOS ONE on average have a comparable or greater impact to those journals that have acceptance rates of $15-20 \%$, despite rejecting only a minority of submissions. Indeed the only journals whose ecological papers consistently have a much greater impact than those in PLOS ONE are Science and Nature. There are two possible explanations as to why the impact of ecological papers in PLOS ONE is comparable to those of ecological journals that are much more selective. The first is that the quality of manuscripts submitted to $P L O S$ $O N E$ are on average higher than those submitted to Ecology, Oikos or Functional Ecology, so that the top $69 \%$ of submissions to PLOS ONE (i.e., those that are accepted) are on par with the top 15-20\% of submissions to the ecological journals and therefore garner similar number of citations. This is scarcely credible; I suspect that few ecologists submit to PLOS ONE in preference to say Ecology (indeed I have heard ecologists sneer about PLOS ONE as the journal that will publish 'anything'), and my own observation is that authors often submit to that journal only after having had their work rejected by the main ecological journals.

This leaves the other explanation, i.e., that the quality of submissions of ecological papers to PLOS ONE and the main ecological journals are probably comparable, that rejections by the main ecological journals to maintain a low acceptance rate are often arbitrary and independent of scientific merit, and that a large proportion of papers rejected by ecological journals are just as important for the scientific record and just as likely to be well cited as those that they do accept. If this is the case, then the assumption that rejecting a large proportion of submissions will result in a higher average quality of published papers that garner a larger numbers of citations and boost the journal's impact factor, is largely unsupported from this analysis. The only exception is for multidisciplinary journals devoted to publishing landmark papers such as Science and Nature, and to a considerably lesser extent, Ecology Letters (widely seen as a third choice after rejection by Science and Nature).

This has two knock-on implications, neither of which is good for the progress of ecology. First, it means that a large proportion of papers rejected by the main ecological journals are likely to be just as important and worthy of publication as those that they do publish. Often these rejections arguably have nothing to do with scientific merit, and can result from poor quality reviewing, editors considering only the most negative of the reviews a manuscript attracts (whether fair or not), and arbitrary editorial decisions to reject manuscripts without review on the basis of what is 'interesting' or 'novel'. Second, because increasing rejection rates mean that many manuscripts are submitted to three or four (or more) journals before the authors strike it 'lucky', there is an ever increasing burden on reviewers, with many reviewers receiving several requests to review manuscripts each week, and with journals finding it increasingly difficult to find willing or competent reviewers. The net result is a decline in the quality of reviewing and an increase in editorial decisions to reject without review, which further feeds back to the manuscript's fate being determined by factors that have little to do with scientific merit.

Given that the plummeting acceptance rates of major journals is impeding dissemination of research results and thus progress in ecology, and that there is no evidence that when journal acceptance rates are in the order of $10-20 \%$ the papers that they accept are any better than many of those that they reject, a substantial change in culture regarding publication is needed. Further, as nearly all journals are available electronically there is no justification for the main ecological journals to use page 
space limits to justify their ever-increasing rejection rates. This is borne out by the PLOS ONE model, which does not limit the numbers of pages it publishes, and which publishes ecological papers that have just as much impact as those published by several of the most selective ecological journals. As noted by Aarssen (2012), "[r]esearchers have for too long been held captive in the grips of publishers and their dutiful editors who have managed to turn peer review into a tool for the dissemination of impact factor elitism." By embracing new publishing models, for example that used by PLOS ONE, in preference to that being implemented by the main traditional ecological journals, we might escape these grips yet.

\section{References}

Aarssen, L.W. 2012. Are peer-review filters optimal for the progress of science in ecology and evolution? Ideas in Ecology and Evolution 5:9-12. CrossRef 